\title{
MODEL ROBOT TROLI OBJECT FOLLOWER MENGGUNAKAN PIXY CMUCAM5 BERBASIS ARDUINO UNO 328P
}

\author{
Hadian Adam Herman ${ }^{1)}$, Andi Chairunnas ${ }^{1,2, \#)}$ \\ 1,2) IImu Komputer, FMIPA, Universitas Pakuan, Bogor, Indonesia \\ \#) Corresponding Author: andi.chairunnas@yahoo.com
}

Article history: received 4 March 2019; revised 25 May 2019; accepted 15 june 2019

\begin{abstract}
Abstrak
Object Follower Robot adalah robot yang dapat mengikuti gerak objek kemana objek itu akan berjalan akan diikuti. Sistem kontrol menggunakan driver motor dan dua buah dinamo untuk menjalankan robot berdasarkan warna objek yang dideteksi oleh kamera Pixy CMUCAM5 sehingga dapat berjalan mengikuti objek. Sistem ini bergantung pada hardware dan software. Hardware menggunakan Arduino Uno 328P sebagai mikrokontrollernya, sensor ultrasonik sebagai pendeteksi jaraknya, kamera Pixy CMUCAM5 sebagai pendeteksi warna objeknya, dan sensor berat HX711 sebagai penimbang belanjaannya. Serta software menggunakan color filtering untuk membaca warna daripada objeknya, hasil yang dikeluarkan dari color filtering inilah yang dibuat konversinya sebagai sistem kontrol robot tersebut. Hasil dari pengujian adalah mengidentifikasi bagaimana robot dapat mengikuti objek, seberapa jauh robot dapat mengikuti objek, serta berapa lama robot mampu berjalan jika robot dinyalakan terus menerus. Sehingga dapat diketahui sejauh mana kemampuan robot dapat digunakan
\end{abstract}

Kata kunci: robotik, object follower, color filtering, pixy CMUCAM5, arduino.

\begin{abstract}
Object Follower Robot is a robot that can follow the object's motion where the object will walk will be followed. The control system uses a motor driver and two dynamos to run the robot based on the color of the object detected by the Pixy CMUCAM5 camera so that it can walk following the object. This system depends on hardware and software. The hardware uses the Arduino Uno $328 \mathrm{P}$ as the microcontroller, the ultrasonic sensor as a distance detector, the Pixy CMUCAM5 camera as the color detector of the object, and the HX711 weight sensor as a weighing counter for shopping. As well as software using color filtering to read colors rather than objects, the results issued from color filtering are what make the conversion as a robot control system. The results of the test are to identify how the robot can follow the object, how far the robot can follow the object, and how long the robot is able to walk if the robot is turned on continuously. So it can be seen the extent to which the ability of the robot can be used.
\end{abstract}

Keywords: robotics, object follower, color filtering, pixy CMUCAM5, arduino.

\section{Pendahuluan}

Perkembangan teknologi sangatlah pesat apalagi dengan adanya revolusi industri 4.0 semakin banyak orang tergugah untuk melakukan inovasi dalam berbagai bidang dengan tujuan untuk mempermudah perkerjaan manusia, mempercepat waktu kerja, membantu usaha manusia, penggunaan tenaga yang sedikit semuanya adalah tujuan teknologi saat ini. Robot dibuat untuk tujuan mempermudah manusia dalam pekerjaannya. Robot adalah rangkaian mekanisme elektronika yang membantu atau meringankan pekerjaan manusia dan membantu mengatasi masalah yang membatasi manusia untuk melakukannya, untuk itu robot diperlukan. Pada penelitian ini robot akan menggunakan 4 roda penggerak. Robot object tracking robot menggunakan robot beroda 4 untuk sistem penggeraknya dengan tujuan mencari object [1]. 
Meskipun mempunyai fungsi yang berbeda dengan model pada penelitian ini akan tetapi memiliki kesamaan dalam sistem penggeraknya. Model troli ini merupakan pengaplikasi robot object follower menggunakan kamera sebagai sensing. Robot beroda Omni, dikembangkan dengan sistem penglihatan warna (Pixy CMUcam5) untuk pelacakan dan mengikuti bola [2]. Pengolahan citra menjadi dasar pergerakan robot beroda. Pengolahan citra adalah proses pengolahan data dengan teknik tertentu dengan masukan berupa gambar pada sistem komputer. Pengolahan citra ini di bagi dalam dua teknik pengolahan, yaitu pengolahan citra dengan keluaran berupa gambar, dan pengolahan citra dengan keluaran berupa keputusan hasil analisis citra. Pada penelitian ini digunakan teknik dengan hasil analisa citra. Object tracking untuk mendeteksi object menggunakan Raspberry $\mathrm{Pi}$ dengan menggunakan computer vision atau image processing sehingga objek terdeteksi dengan akurat [5], hal ini sama konsepnya dengan peneliti yang menggunakan Pixy CMUCam5 sebagai input untuk image processing-nya [3].

Prosesor dual core NXP LPC4330 yang tertanam di kamera Pixy CMUCam5 menjadi tempat pengolahan citra, sehingga ketika disatukan dalam satu sistem maka mikrokontroler tidak akan terbebani dengan proses pembacaan data. Kamera Pixy CMUCam5 mampu melakukan pengolahan gambar yang terintegrasi dan dapat melacak warna tertentu dalam kurun wakru bersamaan [4]. Objek yang digunakan adalah kertas berwarna dengan bentuk bulat. Aplikasi pixyMon dapat digunakan untuk mengenali objek yang sudah ditandai melalui aplikasi ini. Kamera ini memiliki sudut pandang 750 horisontal. Dengan cara menentukan titik koordianat objek terhadap jarak pandang kamera, akan menjadi dasar pemrograman di mikrokontroler Arduino untuk mengatur gerak 4 motor. Arduino akan menerima hasil pengolahan citra dari kamera pixy CMUCam5, Sedangkan pada penelitian kali ini objek yang digunakan adalah gelang berwarna mencolok. Komunikasi yang digunakan dalam menerima data dari kamera pixy CMUCam 5 ada banyak jenis diantaranya adalah komunikasi SPI ( Serial Pheriperal Interface ), I2C (InterIntergrated Circuit), dan USART bisa juga dengan menggunakan pin Digital dan Analog akan tetapi terbatas data yang dikirim dibandingkan menggunakan Komunikasi yang lainnya. Didalam penelitian ini peneliti menggunakan komunikasi I2C untuk transfer data.

\section{Metode Penelitian}

\section{a. Perencanaan Proyek Penelitian}

Dalam perencanaan proyek penelitian, terdapat beberapa hal penting yang perlu ditentukan dan dipertimbangkan, antara lain: keterangan awal penelitian, estimasi kebutuhan alat dan bahan, estimasi anggaran dan kemungkinan penerapan dari sistem yang dirancang.

\section{b. Penelitian}

Setelah Perencanaan telah matang dilanjutkan dengan penelitian awal aplikasi yang akan dibuat. Mulai dari pemilihan dan pengetesan komponen (alat dan bahan), kemungkinan rancangan awal dan akhir dalam merancang.

\section{c. Pengetesan Komponen}

Dalam pengetesan komponen dilakukan pengetasan alat terhadap fungsi komponen berdasarkan kebutuhan sistem yang akan dibuat.

\section{d. Desain Sistem Mekanik}

Dalam perancangan perangkat keras, desain mekanik merupakan hal penting yang harus diperhatikan antara lain: dimensi dan massa keseluruhan sistem, ketahan dan fleksibilitas terhadap lingkungan, penempatan modul modul elektronik, pengetesan sistem yang telah dirancang.

\section{e. Desain Sistem Listrik}

Dalam sistem listrik terdapat beberapa hal yang harus diperhatikan antara lain: sumber catu daya, desain driver pendukung aplikasi, dan skematik sistem alat.

\section{f. Desain Perangkat Lunak}

Perangkat lunak yang pada umumnya dibutuhkan pada tahap perancangan perangkat keras antara lain, software untuk sistem control alat (aplikasi) dan software interface pada Arduino Uno. Pada aplikasi standalone (berdiri sendiri) yang tidak membutuhkan kontrol ataupun dengan PC, hanya dibutuhkan software untuk kontrol dalam alat yang didesain.

g. Tes Fungsional

Tes fungsional dilakukan integrate sistem listrik dan software yang telah didesain. Tes ini dilakukan untuk meningkatkan performa dari perangkat lunak untuk pengontrolan desain listrik dan mengeliminasi error (bug) dari software tersebut. 
KOMPUTASI (Jurnal IImiah IImu Komputer dan Matematika)

Vol. 16, No. 2, Juli 2019, Hal. $263-270$

P-ISSN: 1693-7554, E-ISSN: 2654-3990

\section{h. Integrasi atau Perakitan}

Modul listrik yang diintregrasikan dengan software di dalam kontrollernya, diintegrasikan ke dalam struktur mekanik yang telah dirancang. Lalu dilakukan tes fungsional keseluruhan sistem.

i. Tes Fungsional Keseluruhan Sistem

Pada tahap ini dilakukan pengetesan fungsi dari keseluruhan sistem. Apakah dapat berfungsi sesuai dengan konsep atau tidak. Bila ada sistem yang tidak dapat bekerja dengan baik maka harus dilakukan perbaikan sesuai proses perakitan ulang pada setiap desain sistemnya.

\section{Hasil dan Pembahasan}

Hasil dan pembahasan akan menunjukan uji validasi sistem yang telah dicoba antara lain:

a. Pengujian pada sistem mikrokontroller Arduino Uno

Pengujian minimum mikrokontroller Arduino Uno dilakukan dengan memberikan tegangan $5 \mathrm{~V}$ dengan indikator awal led akan menyala. Berikut pengujian Arduino Uno ditunjukkan pada Gambar 1.

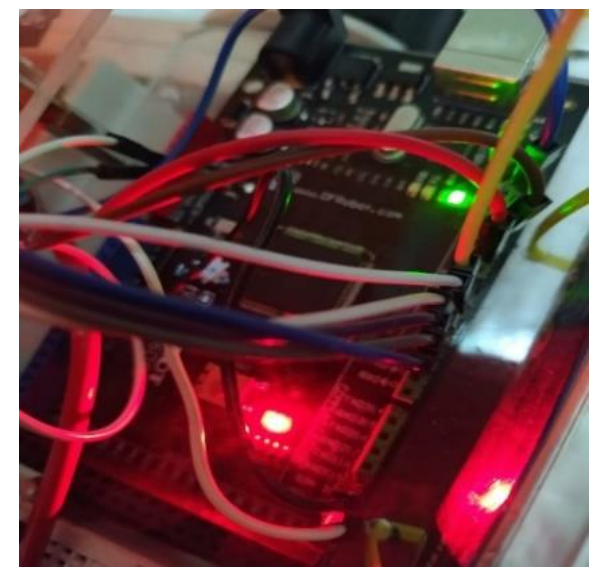

Gambar 1. Pengujian mikrokontroller Arduino

b. Pengujian pada baterai

Rangkaian yang dibuat tentunya perlu ada sebuah tegangan masukkan yang fungsinya, yaitu sebagai pemberi tegangan agar rangkaian yang dibuat dapat berjalan dengan baik. Sedangkan, untuk tegangan masukan itu sendiri diberi tegangan sebesar $12 \mathrm{~V}$ untuk driver motor dan 9V untuk Arduino Uno. Berikut ini pengujian pada baterai menggunakan multimeter ditunjukan pada Gambar 2.

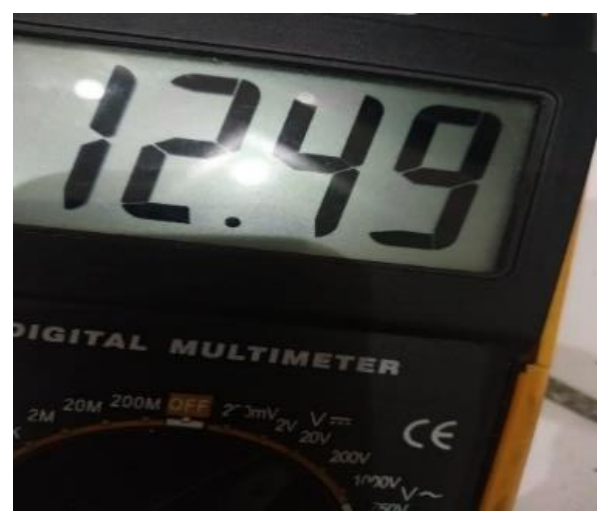

Gambar 2. Pengujian pada baterai 


\section{c. Pengujian pada sensor ultrasonik}

Tabel pengujian sensor ultrasonik ini dilakukan untuk mengetahui jarak yang terbaca di ultrasonik dengan jarak sebenarnya cocok atau tidak. Dilakukan dengan 10 kali percobaan dari jarak dekat hingga jauh.

Tabel 1. Pengujian sensor ultrasonik

\begin{tabular}{|c|c|c|}
\hline Percobaan & $\begin{array}{c}\text { Jarak Ultrasonik } \\
\text { (cm) }\end{array}$ & Jarak Asli (cm) \\
\hline 1 & 5 & 5,2 \\
\hline 2 & 10 & 10,1 \\
\hline 3 & 15 & 15,0 \\
\hline 4 & 20 & 20,1 \\
\hline 5 & 25 & 25,2 \\
\hline 6 & 30 & 30,2 \\
\hline 7 & 35 & 35,3 \\
\hline 8 & 40 & 40,1 \\
\hline 9 & 45 & 45,0 \\
\hline 10 & 50 & $50, .2$ \\
\hline
\end{tabular}

d. Pengujian pada sensor berat

Tabel pengujian sensor berat ini dilakukan untuk mengetahui perbandingan berat untuk berat pada sensor dan berat asli, hal ini dilakukan untuk mengetahui tingkat akurasi sensor. Pengujian dilakukan sebanyak 10 kali dengan objek yang beratnya $1 \mathrm{~kg}-5 \mathrm{~kg}$, jika beratnya lebih dari $4 \mathrm{~kg}$ maka led akan menyala.

Tabel 2. Pengujian sensor berat

\begin{tabular}{|c|c|c|c|}
\hline Percobaan & $\begin{array}{l}\text { Berat } \\
\text { Sensor }(\mathbf{k g})\end{array}$ & $\begin{array}{l}\text { Berat Asli } \\
\text { (kg) }\end{array}$ & $\begin{array}{l}\text { Kondisi } \\
\text { LED }\end{array}$ \\
\hline 1 & 0,8 & 1,1 & Mati \\
\hline 2 & 1,2 & 1,4 & Mati \\
\hline 3 & 1,3 & 1,5 & Mati \\
\hline 4 & 2,1 & 2,3 & Mati \\
\hline 5 & 2,5 & 2,6 & Mati \\
\hline 6 & 3,2 & 3,4 & Mati \\
\hline 7 & 3,3 & 3,5 & Mati \\
\hline 8 & 4,1 & 4,3 & Nyala \\
\hline 9 & 4,5 & 4,7 & Nyala \\
\hline 10 & 5,0 & 5,6 & Nyala \\
\hline
\end{tabular}

e. Pengujian Pixy CMUCAM5

Pengujian Pixy CMUCAM5 yang menggunakan color filtering akan diuji coba, disini sebagaimana diketahui bahwa metode ini akan memisahkan warna yang sudah dipilih menjadi warna yang akan diikuti dan akan dideteksi koordinat objek tersebut berdasarkan tepinya. Pengujian dilakukan dengan cara mengenalkan warna objek dahulu ke Pixy CMUCAM5 lalu melihat dimana letak koordinat objek tersebut. Setelah mengetahui koordinat objek tersebut maka akan dicarikan sudut derajatnya agar mengetahui range penglihatan kameranya, untuk itu menggunakan rumus trigonometri untuk mengetahui derajat penglihatan dari kamera dengan rumus:

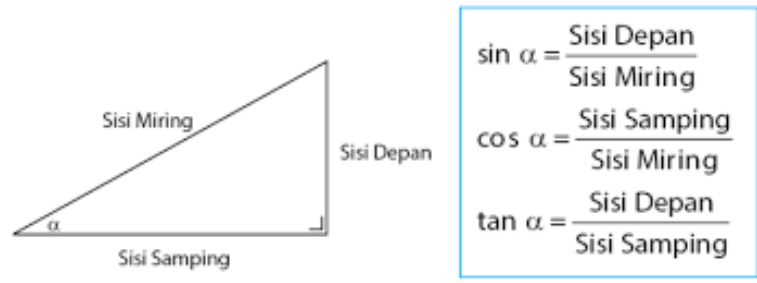

Gambar 3. Rumus trigonometri 
Tabel 3. Pengujian Pixy CMUCAM5

\begin{tabular}{|c|c|c|c|c|}
\hline \multirow[b]{2}{*}{ Percobaan } & \multicolumn{2}{|c|}{ Koordinat } & \multirow[b]{2}{*}{$\begin{array}{c}\text { Sudut } \\
\text { (derajat) }\end{array}$} & \multirow[t]{2}{*}{ Keterangan } \\
\hline & $\begin{array}{c}\mathbf{X} \\
\text { (pixel) }\end{array}$ & $\begin{array}{c}\mathbf{Y} \\
\text { (pixel) }\end{array}$ & & \\
\hline 1 & 46 & 145 & 72,4 & $\begin{array}{l}\text { Objek } \\
\text { disebalah } \\
\text { kiri atas }\end{array}$ \\
\hline 2 & 67 & 40 & 30,8 & $\begin{array}{l}\text { Objek } \\
\text { disebelah } \\
\text { kiri bawah }\end{array}$ \\
\hline 3 & 142 & 134 & 43,3 & $\begin{array}{l}\text { Objek } \\
\text { ditengah }\end{array}$ \\
\hline 4 & 244 & 190 & 37,9 & $\begin{array}{l}\text { Objek } \\
\text { disebelah } \\
\text { kanan atas }\end{array}$ \\
\hline 5 & 286 & 40 & 8 & $\begin{array}{l}\text { Objek } \\
\text { disebalah } \\
\text { kanan } \\
\text { bawah }\end{array}$ \\
\hline 6 & 161 & 64 & 21,7 & $\begin{array}{l}\text { Objek } \\
\text { disebelah } \\
\text { kanan } \\
\text { bawah }\end{array}$ \\
\hline 7 & 104 & 183 & 60,4 & $\begin{array}{l}\text { Objek } \\
\text { disebelah } \\
\text { kanan } \\
\text { tengah }\end{array}$ \\
\hline 8 & 312 & 201 & 32,8 & $\begin{array}{l}\text { Objek } \\
\text { disebelah } \\
\text { pojok kanan } \\
\text { atas }\end{array}$ \\
\hline 9 & 21 & 13 & 31,8 & $\begin{array}{l}\text { Objek } \\
\text { disebelah } \\
\text { pojok kiri } \\
\text { bawah }\end{array}$ \\
\hline 10 & 34 & 214 & 81 & $\begin{array}{l}\text { Objek } \\
\text { disebelah } \\
\text { pojok kiri } \\
\text { atas }\end{array}$ \\
\hline
\end{tabular}

Dari tabel hasil pengujian diatas diketahui bahwa derajat tertinggi didapatkan pada koordinat $\mathrm{x}=34$ dan $\mathrm{y}=214$ yang mana jika objek ditempatkan di sebelah pojok kiri atas maka akan mendapatkan nilai yang tinggi yaitu 81 derajat, sedangkan nilai terendah didapatkan pada koordinat $\mathrm{x}=286$ dan $\mathrm{y}=40$ yang mana jika objek ditempatkan disebelah kanan bawah maka akan mendapatkan nilai rendah yaitu 8 derajat.

\section{f. Pengujian daya tahan baterai}

Baterai yang digunakan adalah baterai li-po (lithium polimer) yang memiliki daya $12 \mathrm{v}$ dan memiliki kapasitas $3300 \mathrm{mAh}$. Dalam pengujian ini diuji berapa lama daya tahan baterai terhadap robot jika berjalan terus-menerus. 
Tabel 4. Pengujian daya tahan baterai

\begin{tabular}{|c|c|c|}
\hline $\begin{array}{l}\text { Waktu } \\
\text { (menit) }\end{array}$ & $\begin{array}{l}\text { Daya } \\
\text { Tersisa } \\
\text { (volt) }\end{array}$ & Keterangan \\
\hline 0 & 12,81 & \\
\hline 15 & 12,49 & \\
\hline 30 & 10,45 & \\
\hline 45 & 9,20 & \\
\hline 60 & 8,96 & \\
\hline 73 & 8,45 & \\
\hline
\end{tabular}

g. Uji Coba Menggunakan 1 Objek

Pengujian robot menggunakan gelang berdimensi $12 \mathrm{~cm} \times 5 \mathrm{~cm}$, uji coba ini dilakukan untuk mengetahui kemampuan robot dalam mengikuti objek yang sudah dikenalkan.

Tabel 5. Pengujian 1 Objek

\begin{tabular}{|c|c|c|c|}
\hline Percobaan & Luas (dpi) & $\begin{array}{l}\text { Jarak } \\
(\mathrm{cm})\end{array}$ & Keterangan \\
\hline 1 & 23423 & 8 & Mengikuti \\
\hline 2 & 20894 & 15 & Mengikuti \\
\hline 3 & 18740 & 20 & Mengikuti \\
\hline 4 & 17450 & 23 & Mengikuti \\
\hline 5 & 14533 & 28 & Mengikuti \\
\hline 6 & 13590 & 40 & Mengikuti \\
\hline
\end{tabular}


KOMPUTASI (Jurnal IImiah IImu Komputer dan Matematika)

Vol. 16, No. 2, Juli 2019, Hal. 263 - 270

P-ISSN: 1693-7554, E-ISSN: 2654-3990

\begin{tabular}{|c|c|c|c|}
\hline 7 & 11654 & 55 & Mengikuti \\
\hline 8 & 3830 & 102 & Mengikuti \\
\hline 9 & 2297 & 120 & Mengikuti \\
\hline 10 & - & 203 & $\begin{array}{c}\text { Tidak } \\
\text { mengikuti }\end{array}$ \\
\hline
\end{tabular}

Pada tabel diatas dapat diketahui bahwa robot hanya dapat mendeteksi objek jika mendapatkan nilai pixel dan nilai pixel ini dipengaruhi oleh jarak semakin luas objek tersebut maka akan semakin dekat, sebaliknya jika semakin kecil pixel objek tersebut maka akan semakin jauh objeknya

h. Uji Coba Menggunakan 2 Objek Berwarna Sama

Pada algoritma color filtering di Pixy CMUCAM5 dapat mendeteksi objek yang warnanya berwarna mencolok agar hue nya stabil, akan tetapi jika ada dua objek yang sama warnanya akan terdeteksi juga oleh kamera, oleh karena itu dilakukan percobaan ini, uji coba ini digunakan gelang yang berukuran $12 \mathrm{~cm} \times 5 \mathrm{~cm}$ untuk objek 1 dan objek 2 menggunakan karton yang berwarna sama berdimensi $26 \mathrm{~cm} \times 10 \mathrm{~cm}$.

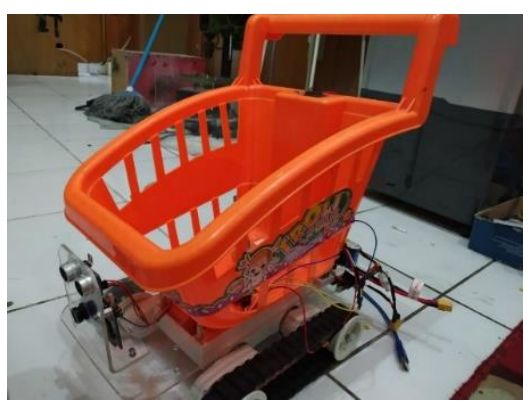

Gambar 4. Foto saat uji coba

Tabel 6. Uji Coba Menggunakan 2 Objek Berwarna Sama

\begin{tabular}{|c|c|c|c|c|c|}
\hline \multirow[b]{2}{*}{ Percobaan } & \multicolumn{2}{|c|}{ Objek 1} & \multicolumn{2}{|c|}{ Objek 2} & \multirow[b]{2}{*}{ Keterangan } \\
\hline & $\begin{array}{l}\text { Luas } \\
\text { (dpi) }\end{array}$ & $\begin{array}{l}\text { Jarak } \\
(\mathrm{cm})\end{array}$ & $\begin{array}{l}\text { Luas } \\
\text { (dpi) }\end{array}$ & $\begin{array}{l}\text { Jarak } \\
(\mathrm{cm})\end{array}$ & \\
\hline 1 & 22433 & 10 & 8305 & 110 & $\begin{array}{c}\text { Robot } \\
\text { mengikuti } \\
\text { objek } 1\end{array}$ \\
\hline 2 & 19367 & 20 & 10640 & 100 & $\begin{array}{c}\text { Robot } \\
\text { mengikuti } \\
\text { objek } 1\end{array}$ \\
\hline 3 & 16234 & 30 & 12204 & 90 & $\begin{array}{c}\text { Robot } \\
\text { mengikuti } \\
\text { objek } 1\end{array}$ \\
\hline 4 & 14509 & 40 & 14343 & 80 & $\begin{array}{c}\text { Robot } \\
\text { mengkuti } \\
\text { objek } 1\end{array}$ \\
\hline 5 & 12428 & 50 & 15896 & 70 & $\begin{array}{c}\text { Robot } \\
\text { mengikuti } \\
\text { objek } 2\end{array}$ \\
\hline 6 & 9942 & 60 & 17985 & 60 & $\begin{array}{c}\text { Robot } \\
\text { mengikuti } \\
\text { objek } 2\end{array}$ \\
\hline 7 & 7934 & 70 & 20964 & 50 & $\begin{array}{c}\text { Robot } \\
\text { mengikuti } \\
\text { objek } 2\end{array}$ \\
\hline
\end{tabular}




\begin{tabular}{|c|c|c|c|c|c|}
\hline 8 & 6327 & 80 & 23494 & 40 & $\begin{array}{c}\text { Robot } \\
\text { mengikuti } \\
\text { objek 2 }\end{array}$ \\
\hline 9 & 4734 & 90 & 26856 & 30 & $\begin{array}{c}\text { Robot } \\
\text { mengikuti } \\
\text { objek 2 }\end{array}$ \\
\hline 10 & 3869 & 100 & 29485 & 20 & $\begin{array}{c}\text { Robot } \\
\text { mengikuti } \\
\text { objek 2 }\end{array}$ \\
\hline
\end{tabular}

Pada tabel diatas dapat diketahui bahwa robot akan mengikuti objek yang lebih besar, hal ini dikarenakan pembacaan Pixy CMUCAM5 yang membaca pixel sebagai patokan untuk seberapa besar dan seberapa dekat objek tersebut.

\section{Kesimpulan}

Model Robot Troli Object Follower Menggunakan Pixy CMUCAM5 Berbasis Arduino Uno 328P pada dasarnya dibuat sebagai pengikut objek yang efektif dalam pengaplikasiannya dalam dunia nyata dan agar bisa digunakan di tempat-tempat publik seperti bandara, supermarket, dan perkebunan.

Berdasarkan hasil uji coba yang dilakukan dapat diambil kesimpulan bahwa Robot Troli Object Follower Menggunakan Pixy CMUCAM5 Berbasis Arduino Uno 328P, fungsi pemrosesan utama berada pada mikrokontroller Arduino Uno 328P sedangkan Pixy CMUCAM5 sebagai prosesor slave dan L298 sebagai penggerak motornya, karena keterbatasan resource pada modul kamera membuat pembacaan dipengaruhi pencahayaan dan keterbatasan pada kualitas gambarnya mempengaruhi pembacaan kamera sangat ketergantungan dengan cahaya dan jarak pembacaannya hanya 81 derajat saja.

Kelebihannya dengan Pixy CMUCAM5 yang powerfull karena dapat membaca kurang lebih 50 frame per second sehingga pemrosesan pada Arduino Uno tidak terlalu berat sehingga pembacaannya mulus dan robot dapat berjalan dengan maksimal mengikuti objek. Dapat membaca objek hingga 81 derajat. Kekurangannya jika ada dua objek yang memiliki warna yang mirip dan ukuran yang hamper mirip maka Pixy CMUCAM5 akan membaca juga objek tersebut sehingga pergerakan robot akan menjadi kurang responsif. Hal ini dikarenakan kamera Pixy CMUCAM5 hanya membaca objek berdasarkan warna dan ukuran objek tersebut.

\section{Referensi}

[1] M. Karthikeyan, M.Kudalingam, P.Natrajan, K.Palaniappan and A.Madhan Prabhu. 2016. Object Tracking Robot by Using Raspberry PI with open Computer Vision (CV).

[2] Ismael, O. Y., \& Hedley, J. 2016. Development of an Omnidirectional Mobile Robot Using Embedded Color Vision System for Ball Following. American Scientific Research Journal for Engineering, Technology, and Sciences (ASRJETS), 22(1), 231-242.

[3] Laksono Budi Prianggodo. 2016. Perancangan Object Tracking Robot Berbasis Image Processing Menggunakan Raspberry Pi.

[4] Ramadhan Singgih Pradipta. 2016. Prototype Troli Pengikut Otomatis Menggunakan Pengolahan Citra Berbasis Arduino.

[5] Narayan Pandharinath Pawar \& Minakshee M. Patil. 2014. Driver Assistance System based on Raspberry Pi. International Journal of Computer Applications (0975 - 8887). 95(16), pp. 36-39. 